\title{
'The pause': honouring the passing of a patient or a collective countertransference for healthcare providers?
}

\author{
David J. R. Morgan ${ }^{*}$ (1)
}

(C) 2019 Springer-Verlag GmbH Germany, part of Springer Nature

Dear Editor,

As an intensivist I have witnessed my fair share of deaths. With each passing I have been respectful of all, reflected on most and grieved for a few. How and when I choose to reflect is personal and dependent greatly on the individual circumstances of each passing. It is therefore with some apprehension that I read the increasingly promoted narrative described as 'the pause' in a recent Intensive Care Medicine opinion piece [1].

Given that there are established societal and religious rituals already designed to aid individuals and communities to express their respect following a person's death, is an additional act necessary? Initially described as a spontaneous moment following an unsuccessful resuscitation, 'the pause' is being increasingly promoted through its own website and endorsing publications [2]. This apparent formalising of a collective process may inadvertently compel some healthcare providers to participate in a pseudo-spiritual act that they are uncomfortable with.

If 'honouring' is a societal end-of-life norm then the patient-centred outcome is probably 'dignity' and respecting a person's autonomy in the end-of-life decision-making process. These discussions require significantly greater physician engagement to ensure that a patient's individual priorities and cultural beliefs are understood in advance of their death. Recognising that expectations may be different in paediatric deaths, with adults there is an increasing use of non-beneficial therapies and inappropriate resuscitation in the final phases of life [3]. As a physician the most respectful action I can undertake at the death of a patient is to ensure that clear, appropriate goals-of-care have been established in advance.

Compliance with ethical standards

Conflicts of interest

The author has no conflicts of interest to disclose.

Ethical approval

Approval by an ethics committee was not applicable.

\section{Publisher's Note}

Springer Nature remains neutral with regard to jurisdictional claims in published maps and institutional affiliations.

Accepted: 8 May 2019

Published online: 27 May 2019

References

1. García-Salido A, Clemente-Garulo D, Escalada-Pellitero S, SerranoGonzález A (2019) A thirty second pause. Intensive Care Med 6:12. https ://doi.org/10.1007/s00134-019-05581-6

2. Ducar DM, Cunningham T (2019) Honoring life after death: mapping the spread of the pause. Am J Hosp Palliat Care 36(5):429-435. https://doi. org/10.1177/1049909118813553

3. Cardona-Morrell M, Kim J, Turner RM, Anstey M, Mitchell IA, Hillman K (2016) Non-beneficial treatments in hospital at the end of life: a systematic review on extent of the problem. Int J Qual Health Care 28(4):456469. https://doi.org/10.1093/intqhc/mzw060.27 